Tohoku J. Exp. Med., 2013, 229, 29-34

\title{
Influenza Vaccination in Autoimmune Rheumatic Disease Patients
}

\author{
Milomir Milanovic, ${ }^{1, *}$ Ljudmila Stojanovich, ${ }^{2, *}$ Aleksandra Djokovic, ${ }^{2}$ \\ Milica Kontic ${ }^{3}$ and Eleonora Gvozdenovic ${ }^{4}$
}

\author{
${ }^{1}$ Clinic for Infectious and Tropical Diseases, Military Medical Academy, Belgrade, Serbia \\ ${ }^{2}$ Department of Internal Medicine, University Medical Centre "Bezanijska Kosa”, Belgrade, Serbia \\ ${ }^{3}$ Clinic for Pulmonology, Clinical Centre of Serbia, Belgrade, Serbia \\ ${ }^{4}$ Clinic for Infectious and Tropical Diseases, Clinical Centre of Serbia, University of Belgrade Faculty of \\ Medicine, Belgrade, Serbia
}

\begin{abstract}
Patients suffering from autoimmune rheumatic diseases have significantly higher risk of developing various infections compared to the healthy population. Our study included patients suffering from systemic lupus erythematosus $(n=30)$, rheumatoid arthritis $(n=37)$ or Sjögren's syndrome $(n=32)$, with stable underlying diseases status. In November 2010, 47 patients, including 35 subjects vaccinated annually during 20062010, received immunization against influenza with trivalent inactivated split vaccine, whereas 52 patients did not accept proposed vaccination in that period. The presence of viral (primarily influenza) and bacterial infections, parameters of disease activity (from the date of vaccination until April 2011), and titers of antibodies against A H1N1 were then monitored in vaccinated and unvaccinated patients. We have identified the importance of predisposing factors for influenza occurrence (i.e. previous respiratory infections and vaccinations in last five years, age, sex, type of disease and duration, medications, smoking) in those groups of patients. The incidence of influenza or bacterial complications (bronchitis) among vaccinated patients was significantly lower, compared to the non-vaccinated group. Importantly, there was no case of exacerbation of the underlying disease. The last vaccination in 2010 reduced the risk of influenza by $87 \%$, but previous bacterial infections (bronchitis and pneumonia) increased influenza risk significantly. In the present study, we have shown the efficiency, sufficient immunogenicity and safety of modern influenza vaccine application in patients suffering from systemic lupus erythematosus, rheumatoid arthritis or Sjögren's syndrome.
\end{abstract}

Keywords: autoimmune rheumatic disease; efficiency; influenza vaccine; respiratory infections; safety Tohoku J. Exp. Med., 2013 Jan, 229 (1), 29-34. C 2013 Tohoku University Medical Press

For many years, vaccination against seasonal influenza in patients suffering from autoimmune rheumatic diseases (AIRD) raised numerous controversies about the efficiency and immunogenicity of vaccination and its harmful effects on the exacerbation of the underlying disease or on inducing new autoimmune disorders.

Patients suffering from systemic lupus erythematosus (SLE), rheumatoid arthritis (RA) and other autoimmune rheumatic diseases have a significantly higher risk of developing various infections compared to the healthy population (Bosch et al. 2006; Glück and Müller-Ladner 2008). Infections are one of the leading causes of mortality in these patients (Doran et al. 2002; Cervera et al. 2003; Falagas et al. 2007). Pulmonary infections are a significant cause of morbidity and mortality in autoimmune rheumatic diseases (Leslie et al. 2007). Viral and bacterial infections in patients suffering from autoimmune rheumatic diseases can have a dramatic course due to the use of aggressive immunosuppressive therapy protocols. This requires correction or even discontinuation of immunosuppressive therapy, which has an additional harmful effect on the clinical activity of the underlying disease (Glück 2006).

The infectious agent (natural or vaccine strain) can act as a stimulant in the activation and potentiation of the immunological response, thus leading to development or exacerbation of chronic autoimmune diseases (Rose 1998; Aron-Maor and Shoenfeld 2004). The role of influenza vaccination in the development of SLE and RA has long been the subject of discussions (Nosal 2000; Shoenfeld and Rose 2004). On the other hand, there are papers about good tolerance of influenza vaccine in patients suffering from SLE and RA, with no significant difference in post vaccination clinical condition as well as in humoral response between patients and healthy control (Del Porto et al. 2006;

Received July 18, 2012; accepted November 7, 2012. Published online December 6, 2012; doi: 10.1620/tjem.229.29.

*These authors contributed equally to this work.

Correspondence: Aleksandra Djokovic, Department of Internal Medicine, University Medical Centre "Bezanijska Kosa”, Autoput bb, Belgrade 11080, Serbia.

e-mail: drsaska@yahoo.com 
Fomin et al. 2006).

The underlying cause for increased susceptibility to infection is the use of immunomodulating medicines (steroids, disease-modifying antirheumatic drugs (DMARDs), biological medicines) and immunoregulatory disorders, which form an integral part of the very nature of autoimmune diseases (Turner-Stokes et al. 1988; Mandell et al. 2010). In addition, due to the long-term administration of immunosuppressive therapy, the efficiency and immunogenicity of vaccine against seasonal flu is usually reduced in patients suffering from autoimmune rheumatic diseases (Saag et al. 2011). However, immunization in immunocompromised patients, including patients suffering from autoimmune rheumatic disease, is the basic strategy for reducing the level of morbidity and mortality linked to the influenza virus (Avery 1999; Conti et al. 2008).

\section{Subjects and Methods}

Our cross-sectional study included three groups of patients (99 in total) suffering from SLE $(n=30)$, RA $(n=37)$ and Sjögren's Syndrome $(n=32)$. Patients were randomly selected from rheumatic reference database based on availability and voluntary consent. There were 85 women (86\%) and 14 men (14\%), and the average age of all patients was $57.65 \pm 11.59$ years, and by groups: SLE, $52.34 \pm 12.49$; RA, $58.68 \pm 11.18$; and Sjögren's Syndrome $(\mathrm{SjS}), 61.28 \pm 9.63$ years.

In November 2010, 47 patients with stable status of underlying diseases were immunized with an inactivated trivalent split vaccine containing $15 \mu \mathrm{g}$ HA A/California/7/2009 (H1N1), $15 \mu \mathrm{g} \mathrm{HA} \mathrm{A}$ Perth/16/2009 (H3N2) and $15 \mu \mathrm{g}$ HA B/Brisbane/60/2008. The control group consisted of 52 patients that did not accept the proposed vaccination in period 2006-2010. We divided the three groups of patients into two subgroups depending on vaccination: vaccinated $\operatorname{SLE}_{1}(n=19), \mathrm{RA}_{1}(n=15)$, and $\operatorname{SjS}_{1}(n=13)$ and unvaccinated $\operatorname{SLE}_{2}(n=11), \mathrm{RA}_{2}(n=22)$, and $\mathrm{SjS}_{2}(n=19)$. The presence of viral (primarily influenza) and bacterial infections, parameters of disease activity (from the date of vaccination until April 2011) and titer of antibodies against A H1N1 were then monitored in vaccinated and unvaccinated patients We did not perform swabs, but performed serological test (the complement fixation test or enzyme-linked immunosorbent assey) to identify common respiratory tract viruses (influenza virus A and B, parainfluenza virus, respiratory syncytial virus, adenovirus, cytomegalovirus, Epstein-Barr virus). Serological testing was performed at the Institute for Virology, Vaccines and Serums "Torlak" in Belgrade (National and World Health Organization (WHO) reference laboratory). We used the hemagglutination inhibition assey (according to the center for disease control and prevention (CDC) method) with influenza virus antigen A/California/7/2009 (H1N1) and turkey erythrocytes for proving antibodies against A H1N1. We have tested 67 sera (47 vaccinated: $\operatorname{SLE}_{1}(n=19), \mathrm{RA}_{1}(n=15)$, and $\mathrm{SjS}_{1}(n=13)$ and 20 unvaccinated: $\operatorname{SLE}_{2}(n=9), \mathrm{RA}_{2}(n=6)$, and $\mathrm{SjS}_{2}(n=5)$ at a dilution of $1 / 8$ to $1 / 1,024$ (no earlier than 10 weeks from start of vaccination). We considered an antibody titer with a dilution of $\geq 1 / 32$ as the protective titer, i.e. the acquired immunity against the pandemic virus, originating from immunization, symptomatic or asymptomatic infection.

We monitored vaccination efficiency via the Geometric Mean Titer (GMT), the mean rank of antibody titers and seroprotective (SP) titer. SP titer $\geq 32$ is generally accepted to be the protective antibody titer.

All patients received symptomatic treatment and antibiotics were applied in the patients with bacterial complications. Antiviral drugs were not administrated.

The study fulfills the ethical guidelines of the most recent declaration of Helsinki (Edinburgh 2000) and has received approval from the ethical committee of Medical Military Academy, Belgrade, Serbia.

\section{Results}

In all subgroups of vaccinated patients $\left(\mathrm{SLE}_{1}, \mathrm{RA}_{1}\right.$, $\mathrm{SjS}_{1}$ ) the vaccine was well tolerated and there were no registered cases of exacerbation of the underlying disease. In the SLE group, influenza infection was detected in 5\% $\mathrm{SLE}_{1}$ and $55 \%$ of $\mathrm{SLE}_{2}$ patients. The difference was statistically significant $(p<0.01)$. A comparison of total viral infections (confirmed clinical types of influenza, subclinical types of influenza and other viral infections) in subgroups $\mathrm{SLE}_{1}$ and $\mathrm{SLE}_{2}(26 \%$ vs. $91 \%)$ revealed a significant difference $(p<0.01)$. In RA patients, the difference in subgroups analyzed regarding influenza occurrence was not significant $(p>0.05)$ but in the incidence of total viral infections was significantly lower in vaccinated RA patients $(p<0.01)$. $\mathrm{SjS}$ patients in the vaccinated group have experienced lower occurrence of influenza and total viral infections compared to the unvaccinated group ( $p<0.05$ and $p<0.01$, respectively). The results are presented on Table 1 and Table 2.

In all patients, we analyzed the respiratory infection incidence during the last season of immunization as well as their relation to the 2010 year vaccination and other predictors such as sex, age, duration of disease, smoking, previous respiratory infections and previous vaccinations during the 2006 - 2010 period. Previous respiratory infections were observed through epidemiological studies and patients' hospital records.

A significant negative correlation was established between vaccinations in 2010 and onset of influenza, a more severe form of influenza, total viral infections and bacterial complications ( $p=0.000, p=0.023, p=0.000$, and $p=0.007$, respectively). We established positive correlation between total viral infections and previous viral infections, bronchitis and pneumonia ( $p=0.050, p=0.000$, and $p=0.013$, respectively) as well as bronchitis and disease duration, smoking, previous bronchitis and pneumonia ( $p=0.039, p=0.029, p=0.000$, and $p=0.000$ respectively). Results are presented on Table 3 .

Using vaccination in the year 2010, previous bronchitis, previous pneumonia, previous vaccinations, and disease type as predictors, we performed a binary logistic regression analysis with influenza as dependent variable. Vaccination reduced the risk of influenza by $87 \%$ (if the values are fixed). Previous bronchitis increases influenza risk approximately eight times (8.041), while previous pneumonia increases this risk by 37 fold (37.358). Previous vaccinations and disease type were not significant predictors. 
Table 1. Respiratory Infections in Various Autoimmune Rheumatic Diseases in Relation to Vaccination 2010.

\begin{tabular}{lccccccccc}
\hline $\begin{array}{c}\text { Disease } \\
n(\%)\end{array}$ & $\begin{array}{c}S L E_{1} \\
n=19\end{array}$ & $\begin{array}{c}S L E_{2} \\
n=11\end{array}$ & $p$ & $\begin{array}{c}R A_{1} \\
n=15\end{array}$ & $\begin{array}{c}R A_{2} \\
n=22\end{array}$ & $\begin{array}{c}S j S_{1} \\
n=13\end{array}$ & $\begin{array}{c}S j S_{2} \\
n=19\end{array}$ & $\begin{array}{c}p \\
13\end{array}$ \\
\hline $\begin{array}{l}\text { INFLUENZA } \\
\text { TOTAL VIRAL }\end{array}$ & $1(5 \%)$ & $6(55 \%)$ & $p<0.01$ & $1(7 \%)$ & $5(23 \%)$ & $\mathrm{NS}$ & $1(8 \%)$ & $8(42 \%)$ & $p<0.05$ \\
INFECTIONS & $5(26 \%)$ & $10(91 \%)$ & $p<0.01$ & $5(33 \%)$ & $19(86 \%)$ & $p<0.01$ & $5(38 \%)$ & $17(89 \%)$ & $p<0.01$ \\
BRONCHITIS & $1(5 \%)$ & $3(27 \%)$ & $\mathrm{NS}$ & $0(0 \%)$ & $3(14 \%)$ & $\mathrm{NS}$ & $1(8 \%)$ & $6(32 \%)$ & $\mathrm{NS}$ \\
PNEUMONIA & $1(5 \%)$ & $2(18 \%)$ & $\mathrm{NS}$ & $0(0 \%)$ & $1(5 \%)$ & $\mathrm{NS}$ & $1(8 \%)$ & $1(5 \%)$ & $\mathrm{NS}$ \\
\hline
\end{tabular}

$P<0.05$ - Difference is significant at the 0.05 level (2-tailed).

$P<0.01$ - Difference is significant at the 0.01 level (2-tailed).

NS, Difference is not significant.

Table 2. Cumulative Presentation of Respiratory Infections in AIRD in Relation to Vaccination 2010.

\begin{tabular}{lccc}
\multicolumn{1}{c}{$\begin{array}{c}\text { Disease } \\
n(\%)\end{array}$} & $\begin{array}{c}\text { AIRD } \\
n=47\end{array}$ & $\begin{array}{c}\text { AIRD } \\
n=52\end{array}$ & $p$ \\
\hline INFLUENZA & $3(6 \%)$ & $19(37 \%)$ & $p<0.01$ \\
TOTAL & $15(32 \%)$ & $46(88 \%)$ & $p<0.01$ \\
VIRAL INFECTIONS & $2(4 \%)$ & $12(23 \%)$ & $p<0.01$ \\
BRONCHITIS & $2(4 \%)$ & $4(8 \%)$ & NS \\
PNEUMONIA & & \\
\hline
\end{tabular}

$P<0.01$ - Difference is significant at the 0.01 level (2-tailed).

NS, Difference is not significant.

Table 3. Pearson's Correlation of Respiratory Infectious with Vaccination and Other Predictors.

\begin{tabular}{|c|c|c|c|c|c|c|c|c|c|}
\hline \multirow{2}{*}{$\begin{array}{c}n(99) \\
2010-2011\end{array}$} & \multicolumn{3}{|c|}{2010} & \multirow[b]{2}{*}{ Age } & \multirow[b]{2}{*}{ Duration } & \multirow[b]{2}{*}{ Smoking } & \multicolumn{3}{|c|}{$2006-2010$} \\
\hline & & $\begin{array}{l}\text { Influenza } \\
\text { Vaccination }\end{array}$ & Sex & & & & $\begin{array}{c}\text { Viral } \\
\text { Infectiones }\end{array}$ & Bronchitis & Pneumonia \\
\hline \multirow[t]{2}{*}{ Influenza } & P.C. & $-.362 * *$ & -.147 & -.124 & -.193 & .123 & .123 & $.477 * *$ & $.507 * *$ \\
\hline & Sig. & .000 & .146 & .224 & .058 & .226 & .224 & .000 & .000 \\
\hline \multirow[t]{2}{*}{ Severe Influenza } & P.C. & $-.229 *$ & -.062 & -.099 & -.107 & .060 & .086 & $.417 * *$ & $.636 * *$ \\
\hline & Sig. & .023 & .543 & .330 & .296 & .557 & .399 & .000 & .000 \\
\hline \multirow[t]{2}{*}{ Total Viral Infections } & P.C.. & $-.581 * *$ & -.037 & -.149 & -.109 & .188 & .197 & $.443 * *$ & $.250 *$ \\
\hline & Sig. & .000 & .714 & .142 & .284 & .063 & .050 & .000 & .013 \\
\hline \multirow[t]{2}{*}{ Bronchitis } & P.C.. & $-.270 * *$ & -.082 & -.074 & $-.209 *$ & $.219 *$ & .094 & $.476 * *$ & $.678 * *$ \\
\hline & Sig. & .007 & .423 & .471 & .039 & .029 & .357 & .000 & .000 \\
\hline \multirow[t]{2}{*}{ Pneumonia } & P.C. & -.072 & .018 & -.114 & -.021 & -.055 & .059 & .194 & $.214 *$ \\
\hline & Sig. & .479 & .856 & .263 & .840 & .586 & .565 & .055 & .033 \\
\hline
\end{tabular}

**Correlation is significant at the 0.01 level (2-tailed). PC, Pearson's Correlation.

*Correlation is significant at the 0.05 level (2-tailed). Sig., significant.

Among the vaccinated patients (47), previous vaccinations were registered in 35 patients (74\%) in last five years. Using partial correlation analysis we demonstrated no significant effect of previous vaccination on the concentration of A H1N1 antibodies i.e. higher antibody titer in vaccinated patients is solely a result of vaccinations in 2010 year.

The established post vaccination geometric mean titers (GMT) of antibodies against A H1N1 were 84.17 in vaccinated and 8.80 in unvaccinated patients. The difference was statistically significant ( $p=0.008$ ). The mean ranks of antibody titers were 39.48 in vaccinated and 19.75 in unvaccinated patients, and the difference was also statisti- cally significant. The highest GMT of anti-influenza antibodies was in the $\mathrm{SLE}_{1}$ subgroup, 141.05, while in the $\mathrm{SLE}_{2}$ subgroup it was $8.89(p=0.018)$. The mean rank of $\mathrm{SLE}_{1}$ subgroup was higher than that of $\mathrm{SLE}_{2}$ subgroup (17.68 and 7.78 respectively, $p=0.002$ ). Subgroups $\mathrm{RA}_{1}$ and $\mathrm{SjS}_{1}$ had a lower humoral response, with no significant differences in GMT compared to unvaccinated patients $\left(\mathrm{RA}_{1} 38.88\right.$ vs. $\mathrm{RA}_{2}-5.33$ and $\mathrm{SjS}_{1} 49.85$ vs. $\mathrm{SjS}_{2}$ 12.80). Despite numerical differences in titer rank in favor of vaccinated patients for both RA and SjS groups (29.15 and 33.94, respectively), no significant differences between subgroups were found ( $p=0.075$ and $p=0.109$ respectively). There was no sig- 
nificant difference between groups of patients regarding the mean ranks of antibody titer $(p=0.418)$.

Seroprotective titer $\geq 32$ was present in 22 of 47 vaccinated patients $(47 \%)$ and in 3 of 20 unvaccinated patients $(15 \%)$. The difference was statistically significant $(p<$ $0.05)$.

It has not been proven that the use of immunosuppressants in SLE and RA patients (steroids in combination with methotrexate) significantly influenced the level of the humoral response ( $p=0.278)$.

\section{Discussion}

Contemporary studies have shown that the trivalent split influenza vaccine without adjuvant is safe and immunogenic in patients suffering from SLE or RA. Its use significantly reduces the risk of respiratory infections and exacerbation of autoimmune diseases (Del Porto et al. 2006; Stojanovich 2006). In our paper, the incidences of viral infections (primarily influenza) and other (secondary) bacterial complications (bronchitis) were significantly lower in vaccinated patients, and there was no case of exacerbation of the underlying disease.

Clinical studies on the importance of influenza vaccination as protection against viral infections and bacterial complications are not so common. Most studies mainly evaluated the development of the protective antibody titer after influenza vaccination ( $\geq 40$, established by hemagglutination inhibition assay), as well as the safety of vaccination (van Assen 2011). In our patients we detected the highest post vaccination antibody titers in SLE vaccinated patients compared to RA and $\mathrm{SjS}$ vaccinated patients. Other papers reported a modest reduction or a similar humoral response in SLE patients, but compared to the healthy control group (Brodman et al. 1978; Mercado et al. 2004; Holvast et al. 2006). In several controlled studies in SLE patients a similar humoral response was established after influenza immunization compared to the healthy control group and immunosuppressive therapy has no significant effect on the response to vaccination (Louie et al. 1978; Lu et al. 2011). On the other hand, there are reports indicating a decreased humoral response in SLE patients treated with immunosuppressive therapy (Abu-Shakra et al. 2002; Wiesik-Szewczyk 2010). Our study has shown no significant effect of the administered immunomodulating therapy with hydroxychloroquine, steroids and methotrexate on the level of the post-vaccination humoral response.

Our research has established lower post-vaccination antibody titers in patients suffering from RA and $\mathrm{SjS}$ compared to those suffering from SLE. Numerous authors state similar efficiency of vaccination for RA patients and healthy volunteers, without any significant influence of DMARD's or biological therapy on the humoral response (Elkayam 2006; Rahier et al. 2010). A few recent studies reported a mild or severe impairment of the humoral response after administration of biological therapy in patients suffering from RA (Gelinck et al. 2008; van Assen et al. 2010)

Regardless of the lower post-vaccination antibody titer in $\mathrm{RA}$ and $\mathrm{SjS}$, their GMT is higher than the presumed SP titer. GMT is highest in SLE patients and is significantly higher in vaccinated patients. Our study established sufficient immunogenicity i.e. humoral response of the vaccine and its significant protective role in preventing influenza, total viral (including subclinical forms of influenza) and bacterial infections in vaccinated patients, compared to unvaccinated patients. There have been no significant differences between the frequency of influenza and total viral and bacterial infections, as well as for humoral response between SLE, RA and SjS patients. Regardless of differences in the level of antibody titers, the efficiency of vaccination in these diseases is significant and very similar, primarily as protection against influenza (both clinical and subclinical), as well as indirectly against secondary bacterial complications. Previous viral and bacterial infections were a significant predictor of repeated respiratory diseases, which in itself emphasizes the significance of vaccination against influenza for patients suffering from chronic rheumatic diseases.

In our paper, we have proved that in patients suffering from SLE, RA and SjS the benefits of vaccination by far outweigh potential harmful effects, i.e. that there is a considerably higher potential risk from exacerbation of the underlying disease caused by a viral or bacterial infection than by vaccination. During the six-month follow up period, in vaccinated patients there were no cases of clinical exacerbation of the main disease and all parameters of disease activity remained unchanged.

In spite of strong recommendation of European league against rheumatism (EULAR) regarding regular annual influenza vaccination in patients suffering from autoimmune rheumatic diseases (van Assen et al. 2011a, 2011b), fear from its adverse effects is still present. Nevertheless, the risk of exacerbation of the underlying disease after influenza vaccination should be carefully evaluated comparing to the risk of developing a potentially severe viral infection in unvaccinated patients.

\section{Conclusion}

We have concluded that overall influenza vaccination for patients suffering from SLE, RA or SjS is safe, efficient and sufficiently immunogenic. After several years of the monitoring of the incidence of respiratory infections, it is clearly visible that a high risk for exacerbation of the underlying disease was associated to viral or bacterial infection rather than to the vaccination itself.

\section{Acknowledgments}

We would like to thank all patients who participated in this study and our colleagues from numerous clinics in Serbia. This work was supported by research grant number 175041 for 2011 2014, issued by the Ministry of Science of the Republic of Serbia, and by research grant number TR 32040 for 2011 - 2014, 
issued by the Ministry of Science of the Republic of Serbia.

\section{Conflict of Interest}

The authors declare no conflict of interest.

\section{References}

Abu-Shakra, M., Press, J., Varsano, N., Levy, V., Mendelson, E., Sukenik, S. \& Buskila, D. (2002) Specific antibody response after influenza immunization in systemic lupus erythematosus. J. Rheumatol., 29, 2555-2557.

Aron-Maor, A. \& Shoenfeld, Y. (2004) Vaccination and autoimmunity. In: Infection and autoimmunity, edited by Shoenfeld, Y. \& Rose, N.R., Elsevier B.V., New York, NY, pp. 105-116.

Avery, R.K. (1999) Vaccination of the immunosuppressed adult patient with rheumatologic disease. Rheum. Dis. Clin. North. Am., 25, 567-584.

Bosch, X., Guilabert, A., Pallarés, L., Cerveral, R., Ramos-Casals, M., Bové, A., Ingelmo, M. \& Font, J. (2006) Infections in systemic lupus erythematosus: a prospective and controlled study of 110 patients. Lupus, 15, 584-589.

Brodman, R., Gilfillan, R., Glass, D. \& Schur, P.H. (1978) Influenzal vaccine response in systemic lupus erythematosus. Ann. Intern. Med., 88, 735-740.

Cervera, R., Khamashta, M.A., Font, J., Sebastiani, G.D., Gil, A., Lavilla, P., Mejía, J.C., Aydintug, A.O., ChwalinskaSadowska, H., de Ramón, E., Fernández-Nebro, A., Galeazzi, M., Valen, M., Mathieu, A., Houssiau, F., Caro, N., Alba, P., Ramos-Casals, M., Ingelmo, M. \& Hughes, G.R.; European Working Party on Systemic Lupus Erythematosus. (2003) Morbidity and mortality in systemic lupus erythematosus during a 10-year period: a comparison of early and late manifestations in a cohort of 1000 patient. Medicine (Baltimore), 82, 299-308.

Conti, F., Rezai, S. \& Valesini, G. (2008) Vaccination and autoimmune rheumatic diseases. Autoimmun. Rev., 8, 124-128.

Del Porto, F., Laganà, B., Biselli, R., Donatelli, I., Campitelli, L., Nisini, R., Cardelli, P., Rossi, F. \& D’Amelio, R. (2006) Influenza vaccine administration in patients with systemic lupus erythematosus and rheumatoid arthritis. Safety and immunogenicity. Vaccine, 24, 3217-3223.

Doran, M.F., Crowson, C.S., Pond, G.R., O'Fallon, W.M. \& Gabriel, S.E. (2002) Frequency of infection in patients with rheumatoid arthritis compared with controls: a populationbased study. Arthritis Rheum., 46, 2287-2293.

Elkayam, O. (2006) Safety and efficacy of vaccination against influenza in patients with rheumatoid arthritis. Clin. Dev. Immunol., 13, 349-351.

Falagas, M.E., Manta, K.G., Betsi, G.I. \& Pappas, G. (2007) Infection-related morbidity and mortality in patients with connective tissue diseases: a systematic review. Clin. Rheumatol., 26, 663-670.

Fomin, I., Caspi, D., Levy, V., Varsano, N., Shalev, Y., Paran, D., Levartovsky, D., Litinsky, I., Kaufman, I., Wigler, I., Mendelson, E. \& Elkayam, O. (2006) Vaccination against influenza in rheumatoid arthritis: the effect of disease modifying drugs, including TNF alpha blockers. Ann. Rheum. Dis., 65, 191-194.

Gelinck, L.B., van der Bijl, A.E., Beyer, W.E., Visser, L.G., Huizinga, T.W., van Hogezand, R.A., Rimmelzwaan, G.F. \& Kroon, F.P. (2008) The effect of anti-tumor necrosis factor alpha treatment on the antibody response to influenza vaccination. Ann. Rheum. Dis., 67, 713-716.

Glück, T. (2006) Vaccinate your immunocompromised patients! Rheumatology (Oxford)., 45, 9-10.

Glück, T. \& Müller-Ladner, U. (2008) Vaccination in patients with chronic rheumatic or autoimmune diseases. Clin. Infect. Dis., 46, 1459-1465.
Holvast, A., Huckriede, A., Wilschut, J., Horst, G., De Vries, J.J., Benne, C.A., Kallenberg, C.G. \& Bijl, M. (2006) Safety and efficacy of influenza vaccination in systemic lupus erythematosus patients with quiescent disease. Ann. Rheum. Dis., 65, 913-918.

Leslie, K.O., Trahan, S. \& Gruden, J. (2007) Pulmonary pathology of the rheumatic diseases. Semin. Respir. Crit. Care Med., 28, 369-378.

Louie, J.S., Nies, K.M., Shoji, K.T., Fraback, R.C., Abrass, C., Border, W., Cherry, J.D. \& Imagawa, D. (1978) Clinical and antibody responces after influenza immunization in systemic lupus erythematosus. Ann. Intern. Med., 88, 790-792.

Lu, C.C., Wang, Y.C., Lai, J.H., Lee, T.S., Lin, H.T. \& Chang, D.M. (2011) A/H1N1 influenza vaccination in patients with systemic lupus erythematosus: safety and immunity. Vaccine, 29, 444-450.

Mandell, G.L., Bennett, J.E. \& Dolan, R. (2010) Mandell, Douglas, and Bennett's Principles and Practice of Infectious Diseases, 7th ed., Churchill Livingstone Elsevier, Philadelphia, PA.

Mercado, U., Acosta, H. \& Avendaño, L. (2004) Influenza vaccination of patients with systemic lupus erythematosus. Rev. Invest. Clin., 56, 16-20.

Nossal, G.J. (2000) Vaccination and autoimmunity. J. Autoimmun., 14, 13-15.

Rahier, J.F., Moutschen, M., Van Gompel, A., Van Ranst, M., Louis, E., Segaert, S., Masson, P. \& De Keyser, F. (2010) Vaccinations in patients with immune-mediated inflammatory diseases. Rheumatology (Oxford), 49, 1815-1827.

Rose, N.R. (1998) The role of infection in the pathogenesis of autoimmune disease. Semin. Immunol., 10, 5-13.

Saad, C.G., Borba, E.F., Aikawa, N.E., Silva, C.A., Pereira, R.M., Calich, A.L., Moraes, J.C., Ribeiro, A.C., Viana, V.S., Pasoto, S.G., Carvalho, J.F., França, I.L., Guedes, L.K., Shinjo, S.K., Sampaio-Barros, P.D., Caleiro, M.T., Goncalves, C.R., Fuller, R., Levy-Neto, M., Timenetsky Mdo, C., Precioso, A.R. \& Bonfa, E. (2011) Immunogenicity and safety of the 2009 nonadjuvanted influenza $\mathrm{A} / \mathrm{H} 1 \mathrm{~N} 1$ vaccine in a large cohort of autoimmune rheumatic diseases. Ann. Rheum. Dis., 70, 10681073.

Shoenfeld, Y. \& Rose, N.R. (2004) Infection and autoimmunity. Elsevier Publ, Amsterdam, The Netherlands. pp. 1-747

Stojanovich, L. (2006) Influenza vaccination of patients with systemic lupus erythematosus (SLE) and rheumatoid arthritis (RA). Clin. Dev. Immunol., 13, 373-375.

Turner-Stokes, L., Cambridge, G., Corcoran Oxford, J.S. \& Snaith, M.L. (1988) In vitro response to influenza immunisation by peripheral blood mononuclear cells from patients with systemic lupus erythematosus and other autoimmune diseases. Ann. Rheum. Dis., 47, 532-535.

van Assen, S. (2011) Influenza vaccination in primary and secondary immunodeficiencies. Ipskamp Drukkers, Enschede, The Netherlands. pp. 1-227.

van Assen, S., Agmon-Levin, N., Elkayam, O., Cervera, R., Doran, M.F., Dougados, M., Emery, P., Geborek, P., Ioannidis, J.P., Jayne, D.R., Kallenberg, C.G., Müller-Ladner, U., Shoenfeld, Y., Stojanovich, L., Valesini, G., Wulffraat, N.M. \& Bijl, M. (2011a) EULAR recommendations for vaccination in adult patients with autoimmune inflammatory rheumatic diseases. Ann. Rheum. Dis., 70, 414-422.

van Assen, S., Elkayam, O., Agmon-Levin, N., Cervera, R., Doran, M.F., Dougados, M., Emery, P., Geborek, P., Ioannidis, J.P., Jayne, D.R., Kallenberg, C.G., Müller-Ladner, U., Shoenfeld, Y., Stojanovich, L., Valesini, G., Wulffraat, N.M. \& Bijl, M. (2011b) Vaccination in adult patients with auto-immune inflammatory rheumatic diseases: a systematic literature review for the European League Against Rheumatism evidence-based recommendations for vaccination in adult patients with auto-immune inflammatory rheumatic diseases. 
Autoimmun. Rev., 10, 341-352.

van Assen, S., Holvast, A., Benne, C.A., Posthumus, M.D., van Leeuwen, M.A., Voskuyl, A.E., Blom, M., Risselada, A.P., de Haan, A., Westra, J., Kallenberg, C.G. \& Bijl, M. (2010) Humoral responces after influenza vaccination are severely reduced in patients with rheumatoid arthritis treated with rituximab. Arthritis Rheum., 62, 75-81.

Wiesik-Szewczyk, E., Romanowska, M., Mielnik, P., ChwalińskaSadowska, H., Brydak, L.B., Olesińska, M. \& Zabek, J. (2010) Anti-influenza vaccination in systemic lupus erythematosus patients: an analysis of specific humoral response and vaccination safety. Clin. Rheumatol., 29, 605-613. 